University of San Diego

Digital USD

Spring 5-25-2019

\title{
Using Short Message (SMS) to Deliver Appointment Reminders and Reduce No-Show Rates: An Evidence-Based Practice Project
}

Fernando Serrano

University of San Diego, fserrano@sandiego.edu

Follow this and additional works at: https://digital.sandiego.edu/dnp

Part of the Health Information Technology Commons, Interprofessional Education Commons, Mental and Social Health Commons, and the Nursing Commons

\section{Digital USD Citation}

Serrano, Fernando, "Using Short Message (SMS) to Deliver Appointment Reminders and Reduce No-Show Rates: An Evidence-Based Practice Project" (2019). Doctor of Nursing Practice Final Manuscripts. 95. https://digital.sandiego.edu/dnp/95

This Doctor of Nursing Practice Final Manuscript is brought to you for free and open access by the Theses and Dissertations at Digital USD. It has been accepted for inclusion in Doctor of Nursing Practice Final Manuscripts by an authorized administrator of Digital USD. For more information, please contact digital@sandiego.edu. 
USING SHORT MESSAGE (SMS) TO DELIVER APPOINTMENT REMINDERS AND REDUCE NO-SHOW RATES: AN EVIDENCE-BASED PRACTICE PROJECT

UNIVERSITY OF SAN DIEGO

Hahn School of Nursing and Health Science

Beyster Institute of Nursing

DOCTOR OF NURSING PRACTICE PORTFOLIO

by

Fernando Ebeo Serrano Jr.

A portfolio presented to the

FACULTY OF THE HAHN SCHOOL OF NURSING AND HEALTH SCIENCE UNIVERSITY OF SAN DIEGO

In partial fulfillment of the

requirements for the degree

DOCTOR OF NURSING PRACTICE

May / 2019 
Table of Contents

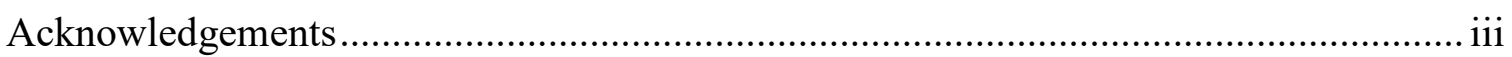

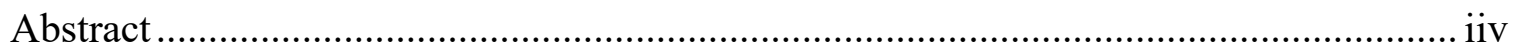

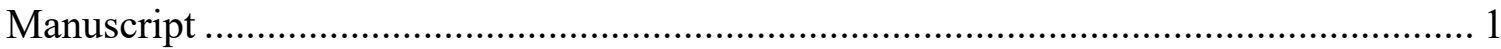

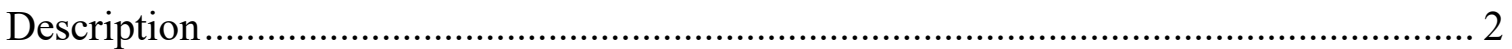

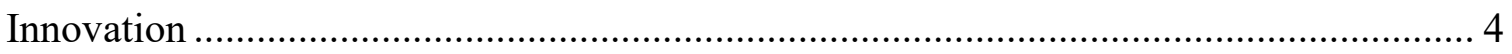

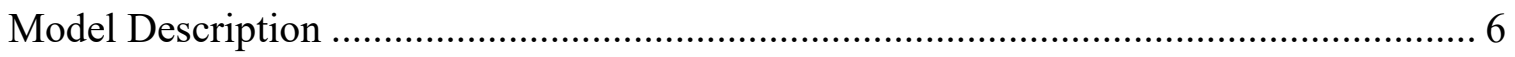

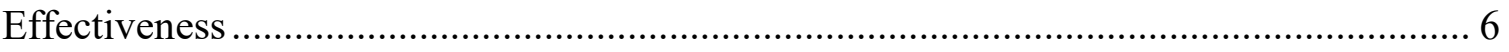

Implications for Clinical Practice and Conclusion ..................................................... 8

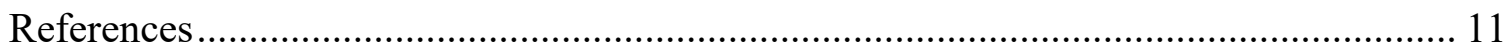




\section{Acknowledgements}

I thank my savior, Jesus Christ, who without his mercy and blessings, I would not have made it this far. I am thankful for my parents, Fernando and Teresita, who have taught me to live with integrity and compassion. I thank my siblings, Caroline and Isaiah, for believing in me every step of the way. I thank my brother-in-law, Peter Fong, for his enthusiasm and for allowing to me to meet my nephew, Carter. I am also thankful to my friends, Edward Brilmyer, John Zhang, and Paul Madayag, for keeping me grounded whenever I strayed off the path. At the same time, I hold a deep gratitude to my friends, Marc Madarang and Edward Page, for reminding why I follow this path.

I thank my faculty advisor, Dr. Michael Terry, for his guidance and patience throughout the nursing program and project. I thank my clinical preceptor, Alexandra Sietsma, for her support and guidance throughout my clinical rotation and project implementation. I thank Janelle Kistler for her help as a technical liaison which allowed the project to go forward. I also thank Judy Davis for her advice on analyzing the data. I thank the staff and administration of Outpatient Psychiatric Services, Hillcrest for their support and cooperation allowing me to conduct my project. I am thankful for my fellow University of San Diego students who have lightened my burdens and allowed me to share my frustrations, letting me know I am never alone. I thank the faculty and administration of the Hahn School of Nursing and Health Science for providing inspiration and excellent guidance. 


\begin{abstract}
Background/Objectives: Missed appointments (MAs) are correlated with reduced treatment efficacy, increased financial burden on medical institutions, and early treatment terminations for therapy (DeFife, Conklin, Smith, \& Poole, 2010). MAs occur for a variety of reasons including, but not limited to severity of illness, financial/geographic constraints, and forgetting the appointment (Filippidou, Lingwood, \& Mirza, 2014). Appointment compliance within outpatient mental health clinics has a wide variance with some clinics reporting MAs ranging from 15\% to 50\% (Car, Gurol-Urganci, de Jongh, Vodopivec-Jamsek, \& Atun, 2013).

With decreasing costs and a subsequent massive increase in mobile phone technology use by the general population, Short Message Services (SMS) has become a new mainstay for direct communication (Brown et al., 2018). Availability of SMS in America is so high that traditionally at-risk populations such as the homeless have access to SMS through the use public outreach programs and prefer SMS reminders (Moczygemba, et al., 2017). These appointment reminders have been implemented in a large variety of clinical settings including, but not limited to outpatient mental health, radiology, physical therapy, and dentistry with each setting experiencing a significant decrease in MAs (Boksmati, Butler-Henderson, Anderson, \& Sahama, 2016). Design: The Iowa model is optimal for this project with interventions tailored to best
\end{abstract} suite an organization with multiple departments invovled.

Setting: At Outpatient Psychiatric Services-Hillcrest (OPS-H), the MAs rate is 18\% among Mental Health Nurse Practitioners (MHNPs) and 33\% with therapy appointments. OPS-H uses the Voicevox automatic phone call service reminder for appointments and on 
September 2018 began mailing patient orientation packets to new patients with driving directions, policy details, and procedure information.

Participants: OPS-H patients seen by PMHNPs and their students for medication management and therapy with both initial intakes and follow-up appointments.

Intervention: University of California San Diego (UCSD) and University of San Diego (USD) Institutional Review Board (IRB) approval were obtained and qualitative statements from PMHNPs and staff regarding attitudes and barriers regarding SMS were gathered. Pre-data collection surveying MAs rates and SMS sign up among PMHNP patients for the previous 8 weeks was conducted.

After pre-data collection was complete, 15 to 30 -minute teaching sessions took place with PMHNP, PMHNP students, and front desk staff. Flyers informing about SMS services were posted in patient waiting rooms. Data was collected weekly for a minimum of 8 weeks with an examination of SMS sign up rates and MAs, along with provider/staff SMS compliance with offering SMS to patients. At the end of the data collection, qualitative statements regarding attitudes and responses to SMS were gathered from PMHNP, PMHNP students, and front desk staff. Throughout the project, data was continually collected on secured cloud and local hard drives with continual tallies on Excel spreadsheets. Case identifiers were limited to alpha numeric codes with no personal information attached.

Measurements: PMHNP and PMHNP student patient no show and SMS sign up rates were collected from August to November 2019.

Results: SMS sign ups increased from $23 \%$ to $61 \%$, attaining statistical significance. MA rates decreased from $15 \%$ to $11 \%$, while approaching statistical significance. 
Conclusion: SMS appointment reminders are favorable to the majority of OPS-H patients. SMS is a cost effective and efficient tool to hep prevent MAs or no-shows. SMS can be beneficial toward decreasing MAs or no-shows.

Key Words: SMS, Text-messages, Appointment-reminders, No-shows, Missed Appointments, mobile phones, smart phones. 


\section{Manuscript}

Using Short Message Services (SMS) to Deliver Appointment Reminders and Reduce No-show Rates: An Evidence-Based Practice Project.

Fenando Ebeo Serrano Jr. MSN, BSN, PCCN

Corresponding author:

Fernando Ebeo Serrano Jr, 1448 Knollwood Place, Chula Vista, CA 91915, 619-207-

8932. Fserrano@sandiego.edu

1. I certify that this work is novel of recent novel clinical research.

2. The potential impact of this evidence-based practice project on clinical care includes the following: increase in SMS sign up rates for OPS-H patients for appointment reminders to reduce MAs. 
Using Short Message Services (SMS) to Deliver Appointment Reminders and Reduce No-Show Rates: An Evidence-Based Practice Project

\section{Description}

Missed appointments (MAs) or No-shows (NS) within the healthcare setting have far reaching effects beyond monetary loss. ${ }^{9} \mathrm{MAs}$, especially in mental health settings, are highly correlated with reduced treatment efficacy, delayed care, negative health outcomes, and early termination of treatment. ${ }^{8}$ Appointment compliance rates within various outpatient settings has a wide variance with clinics reporting MAs as low as $15 \%$ to as high as $50 \%{ }^{6}$ MAs occur for a variety of reasons including, but not limited to severity of illness, financial/geographic constraints, transportation issues, et al, but the most common excuse given by patients is forgetting appointments made over 2 weeks in advance. ${ }^{9}$ Collaborative health care teams incorporating social workers and case managers can assist with many of these issues of socioeconomic constraints. Regarding patients forgetting their appointments, there is a technologically efficient method that is now available with low costs.

Communication is an integral part of human civilization which has continued to evolve along with technology. ${ }^{11}$ The rise of affordable smart phone technologies and mobile telephone Short Message Services (SMS) access have expanded the opportunities for engagement between healthcare providers and patients. ${ }^{18}$ Traditionally vulnerable populations such as the homeless and the impoverished have access to SMS through public outreach programs that provide mobile phones with limited data plans. ${ }^{2,14}$ SMS have been used to help patients with medication adherence, refill reminders, and appointment compliance. ${ }^{14,18,5,6}$ Appointment reminders via SMS have been successfully 
implemented in a large variety of clinical settings ranging from dentistry, HIV clinics, ophthalmology, radiology, physical therapy, psychotherapy, urology, and mental health services with each setting experiencing a decrease in MAs to a varying degree.

1,3,4,5,6,7,1016,17,18,19,20,21 SMS appointment reminders have been used effectively internationally in countries such as England, Saudi Arabia, Kenya, Nigeria, Mozambique, and Scotland. ${ }^{5,16,17,18,20,21}$ Patients surveys show high favorability for SMS appointment reminders over automated and live voice calls, especially among younger age and technically proficient groups. ${ }^{2,3,11,15}$ Patients explain their preference for SMS due to ease of access, brevity of message, and overall convenience with patients that report seldomly answering calls from unfamiliar phone numbers or irregularly reviewing voice messages. ${ }^{2,3}$

Outpatient Psychiatric Services-Hillcrest (OPS-H) is an outpatient mental health services clinic serving a wide range of private and publicly insured clientele with mental health disorders including, but not limited to depression, anxiety, bipolar disorder, schizophrenia, attention-deficit/hyperactivity disorder, and substance use disorder. The average MA rate for patients seeing Psychiatric Mental Health Nurse Practitioners (PMHNPs) was averaging 18\% as of September 2018. Additionally, patients seen for therapy by Marriage Family Therapists (MFTs) and PMHNPs had an MA average of $33 \%$.

The current standard of practice employed by OPS-H to remind patients of upcoming appointments is to first utilize the TeleVox automatic phone call service. This is an automated program which calls patients on the day before their appointment and leaves a voice message informing the patient of the date, time, and place of the 
appointment. This is the default option set for patients due to the policies made to keep compliance with the Health Insurance Portability and Accountability Act (HIPPA). Patients are not automatically signed up for SMS due to vulnerabilities associated with texting to mobile devices. Security concern such as displayed text messages may be seen by third parties, device fragility, stolen/lost devices, or limited connect ability require patients give verbal authorization to a healthcare provider or administrative staff before signing up for SMS reminders. ${ }^{16}$

Another potential barrier for this project was the limited time frame in data collection, as this project was headed by a Doctor of Nursing Practice (DNP) student who had to complete the project by December 2018 and prepare it for information dissemination by February 2019. This limited ability to gather a larger data set over a longer period. Since the project was approved in time for data collection between October 2018 to November 2019, availability of other mental health care providers such as psychiatrists, residents, MFTs, psychologists, and social workers were hindered due to scheduling conflicts and limited availability. This led to the exclusion of tracking patients seen by these providers.

\section{Innovation}

The purpose of this project was to increase SMS sign up rates for patients as a more reliable methodology for appointment reminders and thus decrease the MA rates at OPS-H. The mental health patient population has many issues with patient compliance with appointment attendance as an essential foundation. ${ }^{21} \mathrm{OPS}-\mathrm{H}$ serves a wide culturally diverse demographic from young adults, older adults, civilian, military, et al. most of 
which have access to a mobile device and if not, can be connected to outreach services that can arrange for it.

OPS-H utilizes the EPIC electronic medical health record which has a built-in feature to provide a HIPPA compliant SMS appointment reminder. The project would formally introduce policy and procedures to offer patients the choice to change their appointment reminders from TeleVox to SMS. Once a patient consents to SMS, a text message reminder is sent to their mobile device the day before the appointment identifying the receiver by name and informing them of the date, time, and place of the appointment. They are also given an option to confirm or cancel the appointment. If a patient chooses to cancel the appointment, this would free up open slots for last minute or emergency appointments with mental health providers.

The EPIC system uses wireless internet connectivity to send SMS text reminders, thus incurring no added costs beyond the current data package employed by OPS-H. Patients may use local WiFi internet connections or cellular data to receive these SMS reminders with costs dependent on their current data plans or access to free internet connections provided by public spaces such as local libraries or private businesses.

A 5 to 10 minute in service educational demonstration was developed and presented to PMHNPs, PMHNP students, and front desk staff on how to offer and explain the risks and benefits of SMS appointment reminders. Directions on how to sign patients into service through the EPIC patient demographic interface once permission was granted was also demonstrated. Flyers and advertisements for text message appointment reminders were posted in patient waiting rooms and hallways. PMHNPs, PMHNP 
students, and administrative staff were provided sticky-note instructions that could be placed next to their computer monitors for a reminder.

\section{Model Description}

This project was conducted at OPS-H, a publicly funded mental health clinic in the San Diego area, for 2 months, October 2018 through November 2018, with baseline pre-data collected from August 2018 to September 2018 examining patient SMS sign up and MA rates. Front desk staff were encouraged to offer SMS to all patients not limited to those seen by PMHNPs or PMHNP students. However, psychiatrists, residents, psychotherapists, social workers, and MFTs were excluded from the training due to time constraints and their patients' SMS sign up and MA rates were not tracked or compared.

Data was collected weekly from October 2018 to November 2018, examining SMS sign up rates and MAs among patients seen by PMHNPs and PMHNP students. Informal surveys were conducted with PMHNPs, PMHNP students, and administrative staff to assess compliance with offering SMS to patients and barriers that may occur. At the end of the data collection, qualitative statements regarding attitudes and responses to SMS were gathered from PMHNP, PMHNP students, and front desk staff. During this project, data was continually collected on secured cloud and local hard drives with continual tallies on excel spreadsheets. Case identifiers were limited to alpha numeric codes with no personal information attached.

\section{Effectiveness}

The project found clinical and statistical success in raising SMS sign up rates from $23 \%$ at baseline to $61 \%$ within the course of 2 months. The proportion of patients who took advantage of the text messaging reminder system increased significantly (pre 
$23 \%, \mathrm{n}=190$, post $61 \%, \mathrm{n}=256, \mathrm{p}<0.0001$ ) following the implementation of the project. A small portion of patients refused SMS, stating that they did not have smart phone, or unable to text due to issues with access or trust in the medical establishment. MA rates decreased, however it was not statistically significant. The proportion of patients who kept their appointments after text messaging reminder system increased, but was approaching statistical significance (pre $15 \%, n=350$, post $11 \%, n=391, p=0.0738$ ) following the implementation of the project. While these results are not statistically significant, they are clinically significant.

The lowest cost service offered by OPS-H via pay out of pocket is $\$ 120$, while the highest cost service is $\$ 400$. On average a missed appointment is likely to end up with around \$200 in lost potential revenue. Since there are no SMS licensing fees, additional informational technology consultants or continual operation costs, the only costs would be for initiating the program. Only $\$ 10$ worth of paper and printing material was needed to implement this project with a potential cost of $\$ 300$ to conduct an educational in service for all PMHNPs, PMHNP students, and front desk staff involved. From October 2018 to November 2018, there were 10 less MAs resulting in an average savings of $\$ 2,000$.

Based on these results, a conservative estimate shows a return of investment at $545 \%$, which can be much higher if education/in service training is not conducted beyond regular office hours. An informal qualitative survey of patients revealed patients felt they had an easier time remembering their appointments via SMS and appreciated the ability to confirm or cancel once receiving the message. An informal qualitative survey 
conducted with PMHNPs, PMHNP students, and front desk staff showed positive support for SMS reminders and difficulty interfacing with the EPIC system for SMS sign ups.

\section{Implications for Clinical Practice and Conclusion}

The project fulfilled its objectives of increasing SMS sign up rates among patients at OPS-H, while decreasing MAs. With less MAs, there is a decrease in lost revenue and an increase in provider productivity which helps keep the clinic fiscally responsible. Patients also benefit in having less frustration from missing appointments due to not answering their phone or failing to check their voicemail messages. With SMS, patients also gain the benefit of being able to confirm or cancel/reschedule an appointment due to changing circumstances. Canceled appointments also free up appointment slots for providers to schedule last minute or urgent follow ups during tight

scheduling periods. This also relieves pressure on providers to refill prescriptions without assessing patients first.

Several confounding factors arose while conducting the project which may have interfered with the results. First, the flu season hit San Diego beginning in November 2018. Five patients called to follow up after MAs claimed that they were at home with the flu and did not feel safe to travel to the clinic. Another factor was during the Thanksgiving holiday week, patients reported leaving town to visit distant family and traveling with limited wireless connection, which prevented them from rescheduling. Furthermore, a technical issue also arose which may have limited the ability to sign up project participants. In early November 2019, an upgrade for EPIC slightly changed the 
SMS sign-up interface causing difficulty for front desk staff and PMHNP to sign patients up.

Another area for project improvement pertains to provider compliance regarding offering patients SMS appointment reminders. Sign up rates during the month of October rose quickly, but by mid-November this slowed down. This may be attributed to a lower number of new patients being treated at OPS-H. Another explanation is that provider and front desk compliance was done biweekly and informally, which may have lowered motivation as the project progressed. While SMS sign ups were significantly increased, almost tripling the original percentage, there is still room for improvement.

The MA rates decreased while approaching statistical significance. A longer project length inviting a greater number of participants would gather more data points for comparison and examine if statistical significance can be achieved alongside clinical significance. Other improvements include setting up formal compliance check ins with health providers and front desk staff. Ideally the project can expand to include the previously excluded psychiatrists, residents, MFTs, psychologists, and social workers. Incentives such as gift cards or a complimentary lunch for SMS sign ups milestones completed by providers and staff can also help motivate compliance.

The project will be continued by oncoming PMHNP/DNP students who will be conducting clinicals at OPS-H. They will take over the study while incorporating the improvements mentioned. The project can also evolve into a research study that can examine the correlation between certain diagnoses, SMS appointment reminders, and MAs. 
In conclusion, by utilizing SMS, mental health care providers have an additional deterrent for MAs that is cost effective and efficient. SMS appointment reminders are technologically more favorable to most patients over automatic callers with voice messages. SMS has the potential to increase appointment attendance while reducing provider nonproductive hours. The project is especially valuable since it pertains to the mental health population which has few studies implementing research for this issue. The project has high potential to show statistically and clinically significant decreases in MAs over time, thus helping to prevent lapses or delays in care for patients while promoting appointment compliance and awareness. 


\section{References}

1. Andel, E., Been, S. K., Rokx, C., \& van der Ende, M. E. (2016). Risk factors in an HIV-infected population for refraining from specialist care. AIDS Care, 28(10), 1255-1260. https://doiorg.sandiego.idm.oclc.org/10.1080/09540121.2016.1168914

2. Asgary, R., Sckell, B., Alcabes, A., Naderi, R., Adongo, P., \& Ogedegbe, G. (2015). Perceptions, Attitudes, and Experience Regarding mHealth Among Homeless Persons in New York City Shelters. Journal of Health Communication, 20(12), 1473-1480. https://doiorg.sandiego.idm.oclc.org/10.1080/10810730.2015.1033117

3. Boksmati, N., Butler-Henderson, K., Anderson, K., \& Sahama, T. (2016). The Effectiveness of SMS Reminders on Appointment Attendance: a Meta-Analysis. Journal of Medical Systems, 40(4), 1-10. https://doiorg.sandiego.idm.oclc.org/10.1007/s10916-016-0452-2

4. Brown, W., Giguere, R., Sheinfil, A., Ibitoye, M., Balan, I., Ho, T., Benjamin, Q., Javier, R., Alex, C., Ross, D., Brown, W., 3rd. (2018). Challenges and solutions implementing an SMS text message-based survey CASI and adherence reminders in an international biomedical HIV PrEP study (MTN 017). Journal of Biomedical Informatics, 80, 78-86. https://doiorg.sandiego.idm.oclc.org/10.1016/j.jbi.2018.02.018

5. Car J, Ng C, Atun R, \& Card A. (2008). SMS text message healthcare appointment reminders in England. Journal of Ambulatory Care Management, 31(3), 216-219. Retrieved from 
https://sandiego.idm.oclc.org/login?url=http://search.ebscohost.com/login.aspx?di rect=true \&db=rzh\&AN=105666868\&site $=$ ehost-live

6. Car J, Gurol-Urganci I, de Jongh T, Vodopivec-Jamsek V, \& Atun R. (2013). Mobile phone messaging reminders for attendance at healthcare appointments. Cochrane Database of Systematic Reviews, (12), N.PAG. Retrieved from https://sandiego.idm.oclc.org/login?url=http://search.ebscohost.com/login.aspx?di rect=true \&db=rzh\&AN=108151807\&site=ehost-live

7. Cohen CE, Coyne KM, Mandalia S, Waters AM, Sullivan AK, Cohen, C. E., ... Sullivan, A. K. (2008). Time to use text reminders in genitourinary medicine clinics. International Journal of STD \& AIDS, 19(1), 12-13. https://doiorg.sandiego.idm.oclc.org/10.1258/ijsa.2007.007149

8. DeFife JA, Conklin CZ, Smith JM, \& Poole J. (2010). Psychotherapy appointment noshows: rates and reasons. Psychotherapy, 47(3), 413-417. https://doiorg.sandiego.idm.oclc.org/10.1037/a0021168

9. Filippidou, M., Lingwood S., \& Mirza. I. (2014). Reducing non-attendance rates in a community mental health team. BMJ Open Quality, 3(1) https://doiorg.sandiego.idm.oclc.org/10.1136/bmjquality.u202228.w1114

10. Gullo, M. J., Irvine, K., Feeney, G. F. X., \& Connor, J. P. (2018). Short message service (SMS) reminders improve treatment attendance in alcohol dependence, but are less effective for patients high in impulsivity. Addictive Behaviors, 87, $97-$ 100. https://doi-org.sandiego.idm.oclc.org/10.1016/j.addbeh.2018.06.025

11. Klasnja P, Pratt W, Klasnja, P., \& Pratt, W. (2012). Healthcare in the pocket: mapping the space of mobile-phone health interventions. Journal of Biomedical 
Informatics, 45(1), 184-198. https://doi-

org.sandiego.idm.oclc.org/10.1016/j.jbi.2011.08.017

12. Koshy E, Car J, Majeed A, Koshy, E., Car, J., \& Majeed, A. (2008). Effectiveness of mobile-phone short message service (SMS) reminders for ophthalmology outpatient appointments: observational study. BMC Ophthalmology, 8, 9 . https://doi-org.sandiego.idm.oclc.org/10.1186/1471-2415-8-9

13. Lockhart, T., Gillespie, G. L., \& Grant, V. (2017). An Integrative Review of Text Message Reminders for Medical Surveillance Examinations. Workplace Health \& Safety, 65(8), 372-378. https://doiorg.sandiego.idm.oclc.org/10.1177/2165079916672479

14. Moczygemba, L. R., Cox, L. S., Marks, S. A., Robinson, M. A., Goode, J. R., \& Jafari, N. (2017). Homeless patients' perceptions about using cell phones to manage medications and attend appointments. International Journal of Pharmacy Practice, 25(3), 220-230. https://doiorg.sandiego.idm.oclc.org/10.1111/ijpp.12321

15. Narring, F., Perron, N. J., Dao, M. D., Righini, N. C., Humair, J.-P., Broers, B., ... Haller, D. M. (2013). Text-messaging to reduce missed appointment in a youth clinic: a randomised controlled trial. Journal of Epidemiology \& Community Health, 67(10), 888-891. https://doi-org.sandiego.idm.oclc.org/10.1136/jech$2013-202510$

16. Ossemane, E. B., Moon, T. D., Were, M. C., \& Heitman, E. (2018). Ethical issues in the use of SMS messaging in HIV care and treatment in low- and middle-income countries: case examples from Mozambique. Journal of the American Medical 
Informatics Association, 25(4), 423-427. https://doi-

org.sandiego.idm.oclc.org/10.1093/jamia/ocx123

17. Perry JG. (2011). A Preliminary Investigation into the Effect of the Use of the Short Message Service (SMS) on Patient Attendance at an NHS Dental Access Centre in Scotland. Primary Dental Care: Journal of the Faculty of General Dental Practitioners, 18(4), 145-149. Retrieved from https://sandiego.idm.oclc.org/login?url=http://search.ebscohost.com/login.aspx?di rect $=$ true $\& \mathrm{db}=$ rzh\&AN=108196205\&site $=$ ehost-live

18. Ronen, K., Unger, J. A., Drake, A. L., Perrier, T., Akinyi, P., Osborn, L., Matemo, Daniel; O’Malley, Gabrielle; Kinuthia, John;John-Stewart, G. (2018). SMS messaging to improve ART adherence: perspectives of pregnant HIV-infected women in Kenya on HIV-related message content. AIDS Care, 30(4), 500-505. https://doi-org.sandiego.idm.oclc.org/10.1080/09540121.2017.1417971

19. Taylor, N. F., Bottrell, J., Lawler, K., \& Benjamin, D. (2012). Mobile Telephone Short Message Service Reminders Can Reduce Nonattendance in Physical Therapy Outpatient Clinics: A Randomized Controlled Trial. Archives of Physical Medicine \& Rehabilitation, 93(1), 21-26. https://doiorg.sandiego.idm.oclc.org/10.1016/j.apmr.2011.08.007

20. Thomas, I. F., Lawani, A. O., \& James, B. O. (2017). Effect of Short Message Service Reminders on Clinic Attendance Among Outpatients with Psychosis at a Psychiatric Hospital in Nigeria. Psychiatric Services, 68(1), 75-80. https://doiorg.sandiego.idm.oclc.org/10.1176/appi.ps.201500514 
21. Youssef, A. (2014). Use of short message service reminders to improve attendance at an internal medicine outpatient clinic in Saudi Arabia: a randomized controlled trial. Eastern Mediterranean Health Journal, 20(5), 317-323. Retrieved from https://sandiego.idm.oclc.org/login?url=http://search.ebscohost.com/login.aspx?di rect=true \&db=rzh\&AN=103959487\&site=ehost-live

22. Altman D., Machin, D., Bryant, T., \& Gardner MJ (2000) Statistics with confidence, $2^{\text {nd }}$ ed. BMJ Books. (p. 49)

23. Campbell, I. (2007) Chi-squared and Fisher-Irwin tests of two-by-two tables with sample recommendations. Statistics in Medicine 